\title{
Short communication: The effect of storage conditions and storage duration on milk ELISA results for pregnancy diagnosis
}

\author{
E. M. Wynands, S. J. LeBlanc, and D. F. Kelton ${ }^{1}$ \\ Department of Population Medicine, University of Guelph, Guelph, ON, N1G 2W1 Canada
}

\begin{abstract}
The objective of this study was to evaluate the effect of storage temperature and time from sample collection to analysis on test classification of a commercially available ELISA for diagnosis of pregnancy using the measurement of pregnancy-associated glycoproteins (PAG) in milk samples from dairy cows. Few studies have evaluated the effects of sample handling on milk PAG results. Using a repeated-measures study design, we evaluated sample storage at 5 temperatures: $37^{\circ} \mathrm{C}$, $22^{\circ} \mathrm{C}, 4^{\circ} \mathrm{C},-20^{\circ} \mathrm{C}$, or $-80^{\circ} \mathrm{C}$. Sample aliquots from 45 cows (20 with a pregnant test result, 10 open, and 15 recheck) were stored for $4,7,14,28,60,90$, or 365 d. The measured PAG level was influenced by storage duration and condition. Samples stored for $365 \mathrm{~d}$ had a slightly increased PAG level, whereas samples stored for all other durations showed a slight decline in PAG level compared with the initial result. The reason for an increase in PAG level following long-term storage is not known. This will not affect dairy producers using the test but may be important in samples stored for research applications. The changes in PAG level were small and within the expected variation for this test. Fewer than $6 \%$ of samples changed in classification and, as expected, they were samples near the test interpretation cut-points.
\end{abstract}

Key words: pregnancy diagnosis, pregnancy-associated glycoprotein, sample storage

\section{Short Communication}

The timely and accurate diagnosis of pregnancy in dairy cattle is economically important. Several methods exist to determine pregnancy status of dairy cows. The most commonly used method is rectal examination with or without ultrasound. Chemical tests that detect pregnancy-associated glycoproteins (PAG) as a marker for pregnancy are now commercially available. Pregnancy-

Received February 25, 2017.

Accepted July 31, 2017.

${ }^{1}$ Corresponding author: dkelton@uoguelph.ca associated glycoproteins are members of the aspartic proteinase family and originate from mononucleate and binucleate cells of the embryonic trophoblast (Xie et al., 1997; Green et al., 2000). Pregnancy-associated glycoproteins can be detected in maternal circulation and are a useful marker of pregnancy (Sasser et al., 1986; Zoli et al., 1992). Pregnancy-associated glycoproteins can be used diagnostically starting at $28 \mathrm{~d}$ post-insemination (Green et al., 2005). Several plasma or serum PAG tests are commercially available and have been validated (Silva et al., 2007; Romano and Larson, 2010). Recently, an ELISA for the detection of PAG in milk has been developed and marketed to dairy producers (Idexx Milk Pregnancy Test, Idexx Laboratories Inc., Westbrook, ME). The test uses a microtiter plate coated with an anti-PAG antibody. Captured PAG is measured by colorimetric analysis following the addition of a chromogenic substrate. In a study that included 683 cows from 8 farms, the sensitivity and specificity of the test for confirmation of previously diagnosed pregnancy were reported as 99.2 and $95.5 \%$, respectively, with a prevalence of $97 \%$ pregnant cows in the sample (LeBlanc, 2013). Lawson et al. (2014) found similarly high sensitivity and specificity, 100 and $97.9 \%$, respectively, in 112 cows tested between 33 and $52 \mathrm{~d}$ after insemination.

As farms incorporate chemical pregnancy tests into their reproductive management programs, more research is needed to better understand the effects of handling and storage conditions of samples as they are collected on the farm and shipped to laboratories for processing. Milk samples can be subjected to delays in transit time and exposed to variable and potentially extreme temperature conditions. These delays can be due to the distance that samples must be transported or delays in shipping or processing at the laboratory.

Previous studies have investigated the effect of freezing on PAG ELISA results for blood and serum (Stahmann et al., 2013). The results of these studies showed that PAG levels in blood and serum decreased following freezing and storage for $2 \mathrm{wk}$. No published study has evaluated the impact of sample age and storage temperature on PAG milk ELISA results. 
The objective of this observational study was to use a repeated-measures design with aliquoted samples to determine whether storage temperature or the interval from sample collection to analysis affected the results and interpretation of milk PAG ELISA. The primary objective was to determine whether storage condition could cause a change in test result classification. We hypothesized that no sample would change classification from pregnant to open or open to pregnant following storage at various temperatures.

Milk samples were collected on dairy farms in Ontario by milk recording field staff. The samples were composite samples of all milked quarters for each cow, collected throughout milking into a $50-\mathrm{mL}$ plastic snap-seal vial, and preserved with bronopol. Each bronopol pill contains $43.5 \%$ bronopol and 1.9\% Pimaricin (D\&F Control Products Inc., Dublin, CA). Samples were shipped to a milk-recording laboratory located in Guelph, Ontario, Canada. Milk samples underwent routine testing for fat, protein, and SCC before PAG ELISA testing.

The ELISA kit used for all milk samples in this study was the Idexx Milk Pregnancy Test (Idexx Laboratories Inc.). The assay was performed according to the manufacturer's instructions in an accredited laboratory on equipment that was calibrated monthly against control samples. Briefly, the microtiter plates were prepared by coating an anti-PAG antibody onto the plate. After incubation of the test sample in the coated well, captured PAG was detected with a PAG-specific antibody-horseradish peroxidase conjugate. Unbound conjugate was washed away, and the color-developing substrate was added to the wells. Color development was proportional to the amount of PAG in the sample and was measured using a spectrophotometer. The ELISA reports an $\mathrm{S}$ - $\mathrm{N}$ value, which is the optical density of the sample (S) minus the optical density of the negative control (N) at $450 \mathrm{~nm}$. Based on the manufacturer's guidelines, samples with $\mathrm{S}-\mathrm{N}<0.100$ are classified as not pregnant (open), $\mathrm{S}-\mathrm{N} \geq 0.100$ and $<0.250$ as recheck, and $\mathrm{S}-\mathrm{N} \geq 0.250$ as pregnant. Milk samples tested with the ELISA produce a maximum $\mathrm{S}-\mathrm{N}$ value of 4. The intraplate coefficient of variation for the test is approximately 3.75 to $5.28 \%$ with $\mathrm{S}-\mathrm{N}$ standard deviation (SD) of 0.023 to 0.034 (Idexx, 2014).

During a 4-wk period in January and February 2014, all milk samples that were PAG tested at the laboratory were retained for $24 \mathrm{~h}$ after testing. The following day, the PAG results were used to select samples for inclusion in the study. Milk samples that had a pregnant result within $1 \mathrm{SD}$ of the pregnant cut-off of 0.25 were selected from those available. These samples had $\mathrm{S}-\mathrm{N}$ values between 0.26 and 0.67 . Samples within 1 SD were selected because they would be most at risk of misclassification if the test result changed (decreased) over time or due to storage conditions. Samples that produced recheck results were included as a separate group. When multiple samples met the eligibility criteria, samples were selected purposively. Forty-five milk samples were selected. They were samples with test results classified as pregnant $(\mathrm{n}=20)$, open $(\mathrm{n}=$ $10)$, and recheck $(\mathrm{n}=15)$. The selected samples were aliquoted into fifteen 1.5-mL polypropylene microcentrifuge tubes. Fifteen aliquots were created, and each set of 45 aliquots was subjected to a different set of time and temperature exposures.

Using an effect size of 0.15 ( $\mathrm{S}-\mathrm{N}$ value), which was defined as the smallest difference of interest in the mean value of the outcome variable between pregnant and open samples, and a 2 -sided hypothesis test $(\alpha=$ 0.05 , power $=0.80$ ), it was determined that 7 pregnant samples and 7 open samples would be the minimum number required to detect a change in status from pregnant to open or from open to pregnant. The sample size was inflated to account for the complex composition of milk and the potential for protein degradation.

The temperature conditions included incubation at $37^{\circ} \mathrm{C}$ to represent the extreme heat that samples might be subjected to during shipment in summer; ambient room temperature $\left(22^{\circ} \mathrm{C}\right)$ to represent normal spring or fall daytime temperatures; refrigerated $\left(4^{\circ} \mathrm{C}\right)$, representing mild winter conditions or controlled storage; frozen $\left(-20^{\circ} \mathrm{C}\right)$, representing cold winter conditions or planned storage; and frozen $\left(-80^{\circ} \mathrm{C}\right)$, representing research samples stored for future use. Aliquots were stored for 4, 7, 14, 28, 60, 90, or 365 d. After storage, the aliquots were tested using the same PAG ELISA protocol. Frozen samples were left to thaw at room temperature for $1 \mathrm{~h}$ before testing. Aliquots were discarded after testing. Technicians performing the ELISA were blinded to sample status.

Data were entered into an Excel spreadsheet (Microsoft Corp., Redmond, WA) and exported into SAS version 9.4 (SAS Institute Inc., Cary, NC). All variables were screened for abnormal or missing values, and PROC MEANS was used to generate means, SD, and $95 \%$ CI for PAG results for pregnant, recheck, and open samples at all time points. Categorical variables included storage temperature and time in storage; PAG level was modeled as a continuous variable using mixed linear regression (MIXED procedure in SAS). Sample (cow) was included as a random effect due to multiple observations per sample. Based on univariable analysis, all explanatory variables that produced a $P$-value $<0.20$ were retained for inclusion in the multivariable model. An interaction between temperature and storage time was tested. Manual backward stepwise elimination was used to refine the model until only variables with $P<$ 
Table 1. Descriptive means (SD in parentheses; $95 \%$ CI in brackets) for milk samples initially classified as pregnant $\left[\mathrm{S}-\mathrm{N}^{1}>0.25\right.$ and $<0.67 ; \mathrm{n}=337$, recheck $(\mathrm{n}=180)$, and open $(\mathrm{n}=208)$ over various storage times

\begin{tabular}{lccc}
\hline \multirow{3}{*}{ Time $(\mathrm{d})$} & \multicolumn{3}{c}{ Mean $\mathrm{S}-\mathrm{N}$} \\
\cline { 2 - 4 } & Pregnant $(\mathrm{n}=337)$ & Recheck $(\mathrm{n}=180)$ & Open $(\mathrm{n}=208)$ \\
\hline \multirow{2}{*}{ (initial test) } & $0.47(0.11)$ & $0.17(0.04)$ & $0.02(0.03)$ \\
4 & {$[0.43-0.52]$} & {$[0.14-0.19]$} & {$[0.01-0.04]$} \\
& $0.39(0.09)$ & $0.15(0.04)$ & $0.03(0.04)$ \\
& {$[0.37-0.41]$} & {$[0.14-0.16]$} & $0.02-0.04]$ \\
& $0.48(0.13)$ & $0.16(0.05)$ & $0.03(0.03)$ \\
& {$[0.45-0.52]$} & {$[0.14-0.17]$} & $0.03(0.04]$ \\
28 & $0.47(0.12)$ & $0.17(0.04)$ & {$[0.01-0.06]$} \\
& {$[0.41-0.52]$} & {$[0.14-0.20]$} & $0.03(0.04)$ \\
60 & $0.46(0.12)$ & $0.15(0.04)$ & $0.02-0.04]$ \\
& {$[0.42-0.50]$} & {$[0.14-0.17]$} & $0.03(0.04)$ \\
90 & $0.43(0.09)$ & $0.16(0.03)$ & $0.03(0.04)$ \\
& {$[0.40-0.45]$} & {$[0.15-0.17]$} & {$[0.02-0.05]$} \\
365 & $0.44(0.09)$ & $0.17(0.04)$ & $0.02(0.02)$ \\
& {$[0.41-0.47]$} & {$[0.15-0.19]$} & {$[0.01-0.04]$} \\
\hline
\end{tabular}

${ }^{1}$ The ELISA reports an $\mathrm{S}-\mathrm{N}$ value, which is the optical density (OD) of the sample (S) minus the OD of the negative control $(\mathrm{N})$ at $450 \mathrm{~nm}$. Based on the manufacturer's guidelines, samples with $\mathrm{S}-\mathrm{N}<0.100$ are classified as not pregnant (open), $\mathrm{S}-\mathrm{N} \geq 0.100$ and $<0.250$ as recheck, and $\mathrm{S}-\mathrm{N} \geq 0.250$ as pregnant. The intraplate coefficient of variation was 3.75 to $5.28 \%$ with an S - N SD of 0.023 to 0.034 (Idexx, 2014).

0.05 remained. Variables were considered confounders if there was $>20 \%$ change in the coefficient for PAG. If deemed a confounder, the variable was retained in the model. The model was assessed graphically for outliers and normality of residuals. A contingency table was constructed with the initial sample classification (pregnant, open, or recheck) against the sample classification after storage. Bland-Altman plots, graphing the mean PAG $(\mathrm{S}-\mathrm{N})$ of stored and fresh samples against the difference between PAG $(\mathrm{S}-\mathrm{N})$ for stored and fresh samples, were created (Bland and Altman, 1995).

Due to a laboratory error, results were not available for 6 samples that were stored for $4 \mathrm{~d}$ under the incubated, ambient, refrigerated, and frozen $\left(-20^{\circ} \mathrm{C}\right)$ conditions (24 aliquots). Six replacement samples were selected, stored, and tested. Two aliquots were removed from the analysis $\left(1\right.$ stored at $-20^{\circ} \mathrm{C}$ condition for 90 $\mathrm{d}$, and 1 stored at $-80^{\circ} \mathrm{C}$ condition for $365 \mathrm{~d}$ ) as they had soured and were not tested. Descriptive means of the ELISA results across time in storage are presented in Table 1. The multivariable model is presented in Table 2. Storage condition $(P<0.01)$ and days $(P<$ $0.001)$ were significant in the model, but there was no significant interaction between storage temperature and time $(P=0.67)$. Comparison of sample aliquot interpretation showed that no sample aliquots changed classification from open to pregnant. One sample aliquot changed from pregnant to open. All other sample aliquots that changed classification changed within the recheck range (46 from recheck to open; 20 from re- check to pregnant; 6 from pregnant to recheck; 1 from open to recheck). The mean difference between PAG levels of fresh and stored samples was 0.01, with a $95 \%$ CI of 0.15 to -0.13 . Figure 1 shows the Bland-Altman plot for the subset of samples stored at ambient temperatures for $4 \mathrm{~d}$ and the plot for samples stored frozen $\left(-80^{\circ} \mathrm{C}\right)$ for $365 \mathrm{~d}$ to illustrate the disparity in mean and confidence intervals for samples stored in the short term compared with long term.

There is evidence that sample handling can affect ELISA results (Holten-Andersen et al., 2003), although no studies have been published that address PAG results in milk. Milk samples taken on farm and shipped to a laboratory for testing may experience delays and changes in temperature during transport. Long-term storage of samples is common practice for some research applications. However, little research exists on the validity of results from stored samples.

The results of the multivariable analysis show that both storage duration and temperature had small effects on milk PAG results. The PAG level increased slightly following storage at $4,-20$, or $-80^{\circ} \mathrm{C}$, between 0.01 and 0.02 PAG $(\mathrm{S}-\mathrm{N})$ units, compared with samples stored at $22^{\circ} \mathrm{C}$ for $4-\mathrm{d}, 7-\mathrm{d}$, and fresh samples. For samples stored at $37^{\circ} \mathrm{C}$, PAG level decreased slightly, by 0.02 PAG $(\mathrm{S}-\mathrm{N})$ units, compared with samples stored at $22^{\circ} \mathrm{C}$ for $4 \mathrm{~d}, 7 \mathrm{~d}$, and fresh samples. For storage duration, in samples stored for $4,7,14,28,60$, or $90 \mathrm{~d}$, PAG levels decreased slightly, between 0.01 and 0.05 PAG $(\mathrm{S}-\mathrm{N})$ units, compared with the initial result. The change for samples stored for $365 \mathrm{~d}$ followed a different 
Table 2. Results of the multivariable linear regression model to determine the effect of storage time or temperature on milk pregnancy-associated glycoproteins (PAG) ELISA result (cow included as random effect)

\begin{tabular}{lccccc}
\hline & & \multicolumn{3}{c}{$95 \% \mathrm{CI}$} \\
\cline { 5 - 6 } & & & & \\
Variable & Estimate & $\mathrm{SE}$ & Lower & Upper & $P$-value \\
\hline Intercept & 0.277 & 0.029 & 0.218 & 0.336 & $<0.0001$ \\
Storage temperature $\left({ }^{\circ} \mathrm{C}\right)$ & & & & \\
22 & Referent & & & & \\
37 & -0.015 & 0.009 & -0.032 & 0.002 & 0.077 \\
4 & 0.007 & 0.007 & -0.006 & 0.020 & 0.308 \\
-20 & 0.013 & 0.007 & -0.0002 & 0.026 & 0.053 \\
-80 & 0.022 & 0.009 & 0.005 & 0.039 & 0.012 \\
Storage time (d) & & & & & \\
1 & Referent & & & & \\
4 & -0.039 & 0.008 & -0.056 & -0.023 & $<0.0001$ \\
7 & -0.014 & 0.008 & -0.030 & 0.002 & 0.095 \\
14 & -0.014 & 0.011 & -0.037 & 0.008 & 0.211 \\
28 & -0.032 & 0.011 & -0.053 & -0.011 & 0.0028 \\
60 & -0.050 & 0.012 & -0.071 & -0.029 & $<0.0001$ \\
90 & -0.041 & 0.011 & -0.062 & -0.020 & 0.0002 \\
365 & 0.087 & 0.013 & 0.063 & 0.112 & $<0.0001$ \\
\hline
\end{tabular}

pattern: these increased by 0.09 PAG $(\mathrm{S}-\mathrm{N})$ units compared with the initial PAG result. The reason for an increase in PAG level following long-term storage is not known. It is possible that protein degradation during storage released bound PAG or denatured proteins cross-reacted with the test enzymes. Another possible explanation is that the PAG concentration could have been affected by evaporation or desiccation of the sample. The 365- $\mathrm{d}$ samples changed the most and in a different direction from samples stored for shorter durations. The modeled change in PAG level due to storage condition and duration was too small to cause a major change in sample result classification for most of the samples tested.

The Idexx Milk Pregnancy Test has good repeatability, although small changes are expected due to interplate and interlot variability. The intraplate coefficient of variation for the test is approximately 3.75 to $5.28 \%$ with S - N SD of 0.023 to 0.034 (Idexx, 2014). The differences we observed in PAG level following storage are within this expected variation. Therefore, the small differences could be due to normal variation and not due to storage duration or temperature.

One sample changed classification from pregnant to open. The initial test value for this sample indicated a low pregnant result, and nothing unusual was noted about the sample. No samples changed from open to pregnant. Seventy-three samples changed classification within the recheck range (pregnant or open to recheck; recheck to pregnant or open) and these samples were examined for commonalities. The initial result for the majority of these samples was close to the cut point and only had to change a small amount to switch classification. There was no pattern related to misclassification and storage duration or temperature. The recheck result exists due to biological variation among cows and limitations in repeatability of the test. When a sample receives a recheck result, it is recommended that the cow be retested or examined by a veterinarian. For this reason, samples changing classification around the limits of the recheck range are expected.

Samples with higher PAG values showed higher variability when retested. The Bland-Altman plots for subsets of the data illustrate the difference in pattern for samples stored at $-80^{\circ} \mathrm{C}$ for $365 \mathrm{~d}$ and the samples stored at $22^{\circ} \mathrm{C}$ for $4 \mathrm{~d}$. The latter represents the more likely circumstances under field conditions and there was little bias or change in results. Because of the noted changes in PAG level for the 365-d samples and the Bland-Altman plot results, it appears that long-term storage of milk samples at $-80^{\circ} \mathrm{C}$ for PAG testing is not appropriate and may introduce meaningful error, especially for samples in the pregnant range. BlandAltman plots are used to measure agreement between 2 tests and we acknowledge that using this approach to compare results before and after storage is not the exact application of this statistical measure.

Stahmann et al. (2013) examined the effect of freezing serum and blood samples for 2 wk on PAG level as measured by ELISA. They noted a decline in PAG levels that was concentration dependent, with higher variability and greater declines at higher initial PAG levels. In contrast to the small PAG changes measured in milk, that study found biologically significant declines in PAG. Milk appears to be more stable than blood and serum in regard to PAG level following storage. 
A

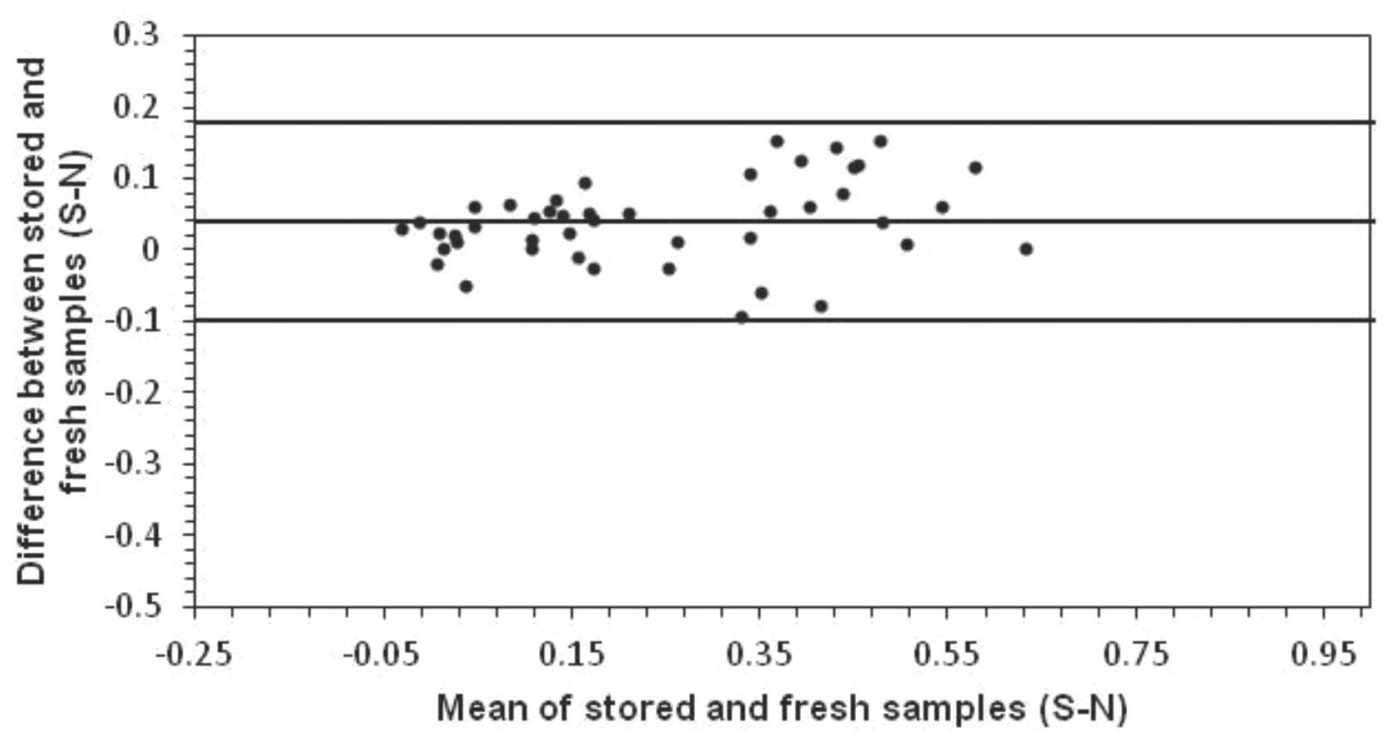

B



Figure 1. Bland-Altman plots of pregnancy-associated glycoproteins (PAG) ELISA milk samples after storage at $22^{\circ} \mathrm{C}$ for $4 \mathrm{~d}(\mathrm{~A}, \mathrm{n}=45)$, and after storage at $-80^{\circ} \mathrm{C}$ for $365 \mathrm{~d}(\mathrm{~B}, \mathrm{n}=44)$. $\mathrm{S}-\mathrm{N}=$ optical density (OD) of the sample (S) minus the OD of the negative control (N) at $450 \mathrm{~nm}$.

Limitations of this study include the assumption that the initial PAG test result captured the true reproductive status (pregnant or open) of the cow. We found no consistent changes in classification among all aliquots for a single sample. This is additionally mitigated by the high sensitivity and specificity of the test. Another limitation was the sample selection process. Samples were selected after arrival and testing at the laboratory and were approximately $3 \mathrm{~d}$ old when they were selected for inclusion in the study and aliquoted. We do not know the conditions that the original samples were exposed to before arrival at the laboratory. It is possible that some degree of protein degradation had occurred in some of the samples. It would be interesting to repeat this study with fresh milk samples.

Overall, PAG level following storage was influenced by storage duration and temperature. The measured change in PAG level was small and the misclassification of pregnant and open samples was minimal. The PAG level in milk appears robust to many storage temperatures and durations, although frozen storage past $90 \mathrm{~d}$ is not recommended. 


\section{ACKNOWLEDGMENTS}

The authors thank CanWest DHI (Guelph, ON, Canada) for providing milk samples and for completing the milk PAG ELISA testing. We also thank the Ontario Veterinary College (Guelph, ON, Canada) for providing project funding.

\section{REFERENCES}

Bland, J. M., and D. G. Altman. 1995. Comparing methods of measurement: Why plotting difference against standard method is misleading. Lancet 346:1085-1087.

Green, J. A., T. E. Parks, M. P. Avalle, B. P. Telugu, A. L. McLain, A. J. Peterson, W. McMillan, N. Mathialagan, R. R. Hook, S. Xie, and R. M. Roberts. 2005. The establishment of an ELISA for the detection of pregnancy-associated glycoproteins (PAGs) in the serum of pregnant cows and heifers. Theriogenology 63:1481-1503. https://doi.org/10.1016/j.theriogenology.2004.07.011.

Green, J. A., S. Xie, X. Quan, B. Bao, X. Gan, N. Mathialagan, J. F. Beckers, and R. M. Roberts. 2000. Pregnancy-associated bovine and ovine glycoproteins exhibit spatially and temporally distinct expression patterns during pregnancy. Biol. Reprod. 62:1624-1631. https://doi.org/10.1095/biolreprod62.6.1624.

Holten-Andersen, M. N., A. S. Schrohl, N. Brünner, H. J. Nielsen, C. K. Høgdall, and E. V. Høgdall. 2003. Evaluation of sample handling in relation to levels of tissue inhibitor of metalloproteinases-1 measured in blood by immunoassay. Int. J. Biol. Markers 18:170-176.

Lawson, B. C., A. H. Shahzad, K. A. Dolecheck, E. L. Martel, K. A. Velek, D. L. Ray, J. C. Lawrence, and W. J. Silvia. 2014. A pregnancy detection assay using milk samples: Evaluation and consid- erations. J. Dairy Sci. 97:6316-6325. https://doi.org/10.3168/jds .2014-8233.

LeBlanc, S. J. 2013. Short communication: Field evaluation of a pregnancy confirmation test using milk samples in dairy cows. J. Dairy Sci. 96:2345-2348. https://doi.org/10.3168/jds.2012-6414.

Idexx. 2014. Milk pregnancy test validation data report. Idexx Laboratories Inc., Westbrook, ME.

Romano, J. E., and J. E. Larson. 2010. Accuracy of pregnancy specific protein-B test for early pregnancy diagnosis in dairy cattle. Theriogenology 74:932-939. https://doi.org/10.1016/j.theriogenology 2010.04.018.

Sasser, R. G., C. A. Ruder, K. A. Ivani, J. E. Butler, and W. C. Hamilton. 1986. Detection of pregnancy by radioimmunoassay of a novel pregnancy-specific protein in serum of cows and a profile of serum concentrations during gestation. Biol. Reprod. 35:936-942.

Silva, E., R. A. Sterry, D. Kolb, N. Mathialagan, M. F. McGrath, J. M. Ballam, and P. M. Fricke. 2007. Accuracy of a pregnancyassociated glycoprotein ELISA to determine pregnancy status of lactating dairy cows twenty-seven days after timed artificial insemination. J. Dairy Sci. 90:4612-4622. https://doi.org/10.3168/ jds.2007-0276.

Stahmann, F., M. Gauly, W. Holtz, and U. König von Borstel. 2013. Short communication: A note on the correction for the effect of freezing on the outcome of pregnancy-associated glycoprotein measurement in blood and serum of cows. J. Dairy Sci. 96:6520-6524. https://doi.org/10.3168/jds.2013-6734.

Xie, S., J. Green, J. B. Bixby, B. Szafranska, J. C. DeMartini, S. Hecht, and R. M. Roberts. 1997. The diversity and evolutionary relationships of the pregnancy-associated glycoproteins, an aspartic proteinase subfamily consisting of many trophoblast-expressed genes. Proc. Natl. Acad. Sci. USA 94:12809-12816.

Zoli, A. P., L. A. Guilbault, P. Delahaut, W. B. Ortiz, and J.-F. Beckers. 1992. Radioimmunoassay of a bovine pregnancy-associated glycoprotein in serum: Its application for pregnancy diagnosis. Biol. Reprod. 46:83-92. 